\title{
CONTROLE DE QUALIDADE EM OBRAS PÚBLICAS - PARCERIA TCE-TO E O CURSO DE ENGENHARIA CIVIL DO IFTO - CAMPUS PALMAS
}

\author{
SALLES NETO, $M$. \\ Professor Titular, Tutor PET-Civil \\ IFTO - Campus Palmas \\ Tocantins; Brasil \\ moacyrsallesneto@gmail.com
}

\author{
AGUIAR, S. J. C. \\ Conselheiro \\ Tribunal de Contas do Estado do Tocantins \\ Tocantins; Brasil \\ severianojca@tce.to.gov.br
}

\author{
SILVA, T. D. A. \\ Professor Doutor; Auditor \\ IFTO - Campus Palmas; TCE-TO \\ Tocantins; Brasil \\ thiagodas@tce.to.gov.br \\ MACEDO, J. A. \\ Auditor \\ Tribunal de Contas do Estado do Tocantins \\ Tocantins; Brasil \\ joselitoam@tce.to.gov.br
}

\section{RESUMO}

A participação popular no âmbito do controle social visa contribuir com controles institucionais, de forma que o cidadão colabore na definição de diretrizes e diagnósticos, na indicação das prioridades, programas e ações, além da avaliação dos resultados obtidos. Ações de estímulo ao exercício da cidadania e instrumentalização desses atores são desenvolvidas em diferentes estados da federação brasileira, sempre com intuito de fortalecer a relação entre sociedade e órgãos de controle. O Tribunal de Contas do Estado do Tocantins (TCE-TO) iniciou em 2017 um conjunto de projetos direcionados aos contratos de obras e serviços de engenharia civil e por isso desenvolvidos em parceria com instituições de ensino superior, especificamente, cursos de Engenharia Civil. As ações desenvolvidas até o presente momento repercutiram de forma significativa no aprimoramento do controle externo. Uma vez firmadas parcerias com três instituições de ensino superior, o projeto é inicialmente desenvolvido no curso de Engenharia Civil do IFTO - Campus Palmas. Até o momento participaram 113 discentes, totalizando 10 manifestações em editais e 14 laudos técnicos representados na ouvidoria do TCE-TO. Todas as obras vistoriadas foram financiadas com recursos públicos e entregues à população, quando da vistoria, há menos de 5 anos.

Palavras-chave: controle social, fiscalização, obras públicas.

\section{ABSTRACT}

The popular participation in the scope of social control aims to contribute with institutional controls so that the citizen collaborates in the definition of guidelines and diagnoses, in the indication of priorities, programs and actions, besides the evaluation of the results obtained. Actions to stimulate the exercise of citizenship and instrumentalization of these actors are developed in different states of the Brazilian federation, always with the purpose of strengthening the relationship between society and control institutions. The Tribunal de Contas do Estado do Tocantins (TCE-TO) started in 2017 a set of projects aimed at civil engineering services contracts and therefore developed in partnership with higher education institutions, specifically Civil Engineering courses. The actions developed to date have had a significant impact on the improvement of external control. Once partnerships are established with three higher education institutions, the project is initially developed in the Civil Engineering course at IFTO - Campus Palmas. So far 113 students have participated, totaling 10 manifestations in notices and 14 technical reports represented at the ombudsman of TCE-TO. All inspect buildings were publicly funded and delivered to the population at the time of the inspect less than 5 years ago.

Keywords: social control, inspection, public works. 


\section{INTRODUÇÃO}

Princípios para participação popular na gestão pública estão estabelecidos na Constituição Federal (BRASIL, 1988) e seus instrumentos são regulamentados por legislações posteriores como a Lei complementar $n^{\circ} 101 / 2000$, de 4 de maio de 2000 (BRASIL, 2000), a Lei de Responsabilidade Fiscal (LRF), e Lei ${ }^{\circ}$ 12.527, de 18 de novembro de 2011 (BRASIL, 2011), a Lei de acesso à informação. Relevantes espaços de participação são garantidos à sociedade a partir das disposições sobre transparência, controle e fiscalização delineadas nesse documento (PASCOAL, FARIAS, 2019).

Conforme definido pela Controladoria Geral da União (CGU), o controle sobre a administração pública "pressupõe examinar se a atividade governamental atendeu à finalidade pública, à legislação e aos princípios básicos aplicáveis ao setor público" (BRASIL, 2019, p.16). Considerando o controle institucional realizado por órgãos como o Tribunal de Contas, a participação popular na perspectiva no controle social define "a participação da sociedade civil na elaboração, acompanhamento e verificação (ou monitoramento) das ações de gestão pública” (RICCI, 2019, p. 69) a fim de garantir $o$ atendimento aos interesses da coletividade.

Essa participação é considerada mecanismo de prevenção da corrupção e de fortalecimento da cidadania (CGU, 2019). O desempenho dessas ações depende tanto da mobilização quanto da orientação sobre como exercer esse papel e quais instrumentos os cidadãos devem utilizar para colaborar com a gestão pública. Ações que convergem para esse fim são implementadas por órgãos de controle de diferentes estados da federação, a exemplo do Tribunal de Contas do Estado do Pernambuco (TCE-PE), e da própria união através da CGU.

O Programa Olho Vivo no Dinheiro Público recebeu o Prêmio Nacional de Excelência na Educação (Prêmio Educare) em 2007 devido às ações de capacitação presencial e à distância promovidas a fim de estimular o controle social sobre os gastos públicos. O Programa TCEndo cidadania, também premiado com Prêmio Educare em 2007 e implementado pela Escola de Contas do TCE-PE visa estimular o controle social através de projetos desenvolvidos em parceria com instituições de ensino e conselhos municipais em cujos fóruns e capacitações discute-se sobre gestão, políticas públicas e fiscalização (SILVA, 2007).

O Tribunal de Contas do Estado do Tocantins (TCE-TO) iniciou em 2017 um projeto de extensão, de objetivos semelhantes aos supracitados, sob a coordenação da Coordenadoria de Análise de Atos, Contratos e Fiscalização de Obras e Serviços de Engenharia (CAENG). A primeira etapa de atividades desenvolveu-se no âmbito do projeto "Fiscalização de obras públicas em parceria com o TCE-TO”. Uma outra etapa foi iniciada pelo Instituto Federal do Tocantins (IFTO) - Campus Palmas, denominada de “Auditorias de Qualidade em Obras Públicas”.

Destacam-se aqui os conceitos de obra e serviços, conforme Lei no 8.666, de 1993 de 21 de junho de 1993 (BRASIL, 1993):

Art. $6^{\circ}$ Para os fins desta Lei, considera-se:

I - Obra - toda construção, reforma, fabricação, recuperação ou ampliação, realizada por execução direta ou indireta;

II - Serviço - toda atividade destinada a obter determinada utilidade de interesse para a Administração, tais como: demolição, conserto, instalação, montagem, operação, conservação, reparação, adaptação, manutenção, transporte, locação de bens, publicidade, seguro ou trabalhos técnico-profissionais. (BRASIL, 1993, online).

Ambos os projetos se utilizam dos dados disponíveis no Sistema Integrado de Controle e Auditoria Pública Licitações, Contratos e Obras (SICAP-LCO) instituído pela Instrução Normativa TCE/TO nº 10 de 11 de dezembro de 2008 (TOCANTINS, 2019). Desde $1^{\circ}$ agosto de 2009, as informações dos atos administrativos, da licitação e informações sobre a execução de obras e serviços de engenharia, são realizadas por meio eletrônico, informações utilizadas como ferramenta de gestão e controle pelos próprios jurisdicionados e também disponíveis ao cidadão através do Módulo Público. As consultas são realizadas a partir da identificação da unidade gestora, do processo de licitação ou objeto contrato.

As principais ações da CAENG estão direcionadas aos contratos de obras e serviços de engenharia civil e por isso desenvolvem-se em parceria com instituições de ensino superior e em cursos de Engenharia Civil, nomeadamente Instituto Federal de Educação, Ciência e Tecnologia do Tocantins (IFTO) Campus Palmas, Universidade Federal do Tocantins (UFT) Campus Palmas e ITPAC Porto Nacional. A seguir serão apresentados os resultados parciais dos projetos executados entre 2017 e 2020. 


\section{METODOLOGIA}

A primeira etapa de atividades objetivou identificar irregularidades nas fases de licitação, contrato e projeto a partir da análise de dados do SICAP-LCO. Discentes e docentes das instituições de ensino superior participaram de capacitação, ministrada pelos auditores do TCE-TO, com duração de quatro horas e realizada nas instalações da instituição de ensino superior ou do TCE-TO. Apresentaram-se temas relativamente aos processos de licitação, editais, modalidades e regimes de contratação à luz da Lei $n^{\circ}$ 8.666, de 1993 de 21 de junho de 1993 (BRASIL, 1993), bem como o acesso ao SICAP-LCO.

As instituições de ensino superior indicam um docente responsável pelas atividades e pela distribuição dos discentes em grupos de trabalho, a fim de segmentar as análises por relatoria. Em ato contínuo, ao acesso e análise dos dados cadastrados no SICAP-LCO, os discentes encaminham, via correio eletrônico, as irregularidades encontradas, como a ausência de informações ou documentos obrigatórios. Essas observações foram encaminhadas aos auditores ministrantes da capacitação, para avaliação e adoção das medidas administrativas cabíveis.

A segunda etapa, desenvolvida pelo IFTO-Campus Palmas, aplicou os conteúdos da disciplina de Patologias das Construções para analisar a qualidade de obras. Dessa forma, os participantes realizaram visitas técnicas para elaboração de laudos técnicos de edificações públicas do Estado do Tocantins, cujas obras ou serviços de engenharia civil foram concluídos até os 5 anos anteriores.

O IFTO-Campus Palmas indicou o docente responsável pelas atividades - o professor da disciplina de Patologias das Construções - assim como pela distribuição dos discentes em grupos de trabalho. Dessa forma, o professor enumerou as edificações enquadradas nos critérios de seleção e que constituíram objeto de estudo dos discentes.

Após a indicação dos objetos de estudo aos grupos de trabalho, os discentes foram responsáveis por coletar informações no módulo público do sistema SICAP-LCO relativamente a: descrição do objeto; processo licitatório; responsáveis pela elaboração de projetos e fiscalização, quando aplicável; dados da obra.

A seguir os grupos de trabalho realizaram visita técnica à edificação para identificação e registro das características das manifestações patológicas, incluso registro fotográfico e mapeamento em planta baixa das patologias. Auxiliados pelas informações do módulo público do sistema SICAP-LCO, especialmente informações de projeto, as observações realizadas na visita técnica foram confrontadas com indicações de regulamentos, normas técnicas e boas práticas, a fim de analisar a: manifestação patológica; causas possíveis; consequências; recomendações.

As análises realizadas pelos grupos de trabalho para cada objeto de estudo foram examinadas pelo docente responsável da instituição de ensino. Após a conclusão dos laudos técnicos, os referidos documentos foram encaminhados ao TCETO via ouvidoria.

\section{DA APLICAÇÃO DO CÓDIGO CIVIL E CÓDIGO DE DEFESA DO CONSUMIDOR (CDC)}

A verificação da qualidade das obras públicas tem como objetivo primordial a necessidade de valorizar os recursos empregados, e que saíram do bolso do cidadão contribuinte. Os altos impostos suportados pela população, infelizmente, não têm se revertido em obras públicas de qualidade, que tenham durabilidade, segurança e funcionalidade almejada.

A aferição da qualidade das obras públicas permite a identificação de possíveis defeitos, ou falhas, momento em que se deve chamar a responsabilidade civil do construtor, no caso, das empreiteiras contratadas pelo poder público.

O objetivo é que a garantia das obras públicas seja acompanhada pelas instituições públicas contratantes. O poder público pode, inclusive, ser processado por particulares, e por consequência os respectivos gestores, pela omissão de não acionar as empresas particulares, por não cumprirem adequadamente a execução das obras públicas.

A Lei de Licitações e Contratos (Lei ${ }^{0}$ 8.666/93), em seu art. 54, preceitua que disposições de direito privado e princípios da teoria geral dos contratos aplicam-se, supletivamente, aos contratos administrativos:

“Art. 54. Os contratos administrativos de que trata esta Lei regulam-se pelas suas cláusulas e pelos preceitos de direito público, aplicando-se-lhes, supletivamente, os princípios da teoria geral dos contratos e as disposições de direito privado.”

Desta forma, tem-se que as disposições do direito privado podem e devem ser aplicadas na verificação das responsabilidades, desde que compatibilizados com os princípios gerais da Administração Pública.

Não restam dúvidas que o Código Civil deve ser aplicado na responsabilização do construtor/empreiteiro, no que diz respeito à segurança e solidez da obra, veja-se o art. 618:

“Art. 618. Nos contratos de empreitada de edifícios ou outras construções consideráveis, o empreiteiro de materiais e execução responderá, durante o prazo irredutível de cinco anos, pela solidez e segurança do trabalho, assim em razão dos materiais, como do solo. 
Parágrafo único. Decairá do direito assegurado neste artigo o dono da obra que não propuser a ação contra o empreiteiro, nos cento e oitenta dias seguintes ao aparecimento do vício ou defeito."

É possível verificar também, no parágrafo único do supracitado artigo, que o dono da obra tem que ser diligente, ou seja, a instituição pública deve acompanhar a possível existência de defeitos ou vícios.

Quanto ao CDC, há entendimentos controversos sobre o tema, porém o Engenheiro/Advogado Carnot Leal Nogueira, Inspetor de Obras Públicas do TCE-PE, em sua publicação “Auditoria de Qualidade de Obras Públicas”, entende que há compatibilidade na aplicação do CDC aos contratos administrativos, e faz um paralelismo de forma que a Administração se coloca como consumidora final, em benefício da coletividade. Evidencia também que o TCU tem decisões no sentido da aplicação do CDC, a exemplo do Acórdão 92/2004 - Segunda Câmara, veja-se trecho:

“(...) Não seria plausível que alguém contratasse uma Empresa para construir uma barragem para ter dois anos de vida, a barragem foi construída para ter vida longa. Essa alegação nega o art. 12 da Lei 8.078/90 - Código de Defesa do Consumidor. (...)”

No que diz respeito à “Garantia Quinquenal” é importante que a Administração atente para verificação da qualidade da obra em tempo oportuno, visto que para a solidez, segurança e funcionalidade, o prazo de garantia é de 05 (cinco) anos, a contar da entrega da obra ao ente contratante. Durante esse prazo a responsabilidade é presumida, bastante e suficiente a constatação de que o problema existe.

Quanto aos vícios ocultos em geral, o prazo se estende pelo período de vida útil do projeto da obra, entretanto, há a necessidade que se prove o vício oculto, o que pode, por vezes dificultar a perfeita satisfação da Administração, e por consequência do contribuinte.

Segue abaixo a tabela 1, elaborada pelo Inspetor do TCE-PE, Carnot Leal Nogueira, dos principais prazos referentes às responsabilidades dos construtores de obras públicas, segundo o Código Civil e o Código de Defesa do Consumidor.

Tabela 1 - Edificações visitadas pelos grupos de trabalho durante segunda etapa de atividades, projeto “Auditorias de Qualidade em Obras Públicas”

\begin{tabular}{|c|c|c|c|c|}
\hline & $\begin{array}{l}\text { Prazo e natureza da } \\
\text { responsabilidade }\end{array}$ & Fundamento legal & $\begin{array}{c}\begin{array}{c}\text { Prazo para acionar o } \\
\text { empreiteiro }\end{array} \\
\end{array}$ & Observações \\
\hline $\begin{array}{c}\text { Solidez, } \\
\text { segurança e } \\
\text { funcionalidade }\end{array}$ & $\begin{array}{l}\text { Prazo de garantia de } \\
5 \text { (cinco) anos, a } \\
\text { contar da entrega da } \\
\text { obra ao ente } \\
\text { contratante. }\end{array}$ & $\begin{array}{c}\text { Art. } 618 \text { do Código } \\
\text { Civil. } \\
\text { Art. } 1.245 \text { do CC de } \\
1916 . \\
\text { Art. 12, II, e art. 6º } \\
\text { IX, da Lei n }{ }^{\circ} \\
\text { 8.666/93. }\end{array}$ & $\begin{array}{l}\text { Prazo de } 180 \text { dias para ações } \\
\text { de natureza constitutiva } \\
\text { (e.g., rescisão contratual) - } \\
\text { par. único do art. } 618 \text { do } \\
\text { CC. } \\
\text { Prazo de } 3 \text { anos para ação de } \\
\text { reparação de danos - art. } \\
\text { 206, } § 3^{\circ}, \mathrm{V} \text {, do CC. } \\
\text { Prazo de } 5 \text { anos para ação de } \\
\text { reparação de danos - art. } 27 \\
\text { do CDC. }\end{array}$ & $\begin{array}{l}\text { Durante o prazo de } \\
\text { garantia, a } \\
\text { responsabilidade do } \\
\text { empreiteiro } \\
\text { pelos problemas de } \\
\text { solidez, segurança e } \\
\text { funcionalidade é } \\
\text { presumida. Para } \\
\text { acioná-lo é } \\
\text { suficiente a } \\
\text { constatação de que o } \\
\text { problema existe. }\end{array}$ \\
\hline $\begin{array}{l}\text { Vícios ocultos } \\
\text { em geral }\end{array}$ & $\begin{array}{c}\text { Prazo para ação } \\
\text { redibitória, correção } \\
\text { do problema ou } \\
\text { abatimento no valor } \\
\text { pago pela obra. } \\
\text { O prazo se estende } \\
\text { por todo o período de } \\
\text { vida útil de projeto da } \\
\text { obra. }\end{array}$ & $\begin{array}{c}\text { Art. } 445, \S 1^{\circ} \text {, do } \\
\text { Código Civil. } \\
\text { Art. 26, } \S 3^{\circ} \text {, do } \\
\text { Código de Defesa } \\
\text { do } \\
\text { Consumidor. }\end{array}$ & $\begin{array}{l}\text { Um ano para redibição ou } \\
\text { abatimento no preço, a partir } \\
\text { do surgimento do vício - art. } \\
\text { 445, § } 1^{\circ} \text {, do CC. } \\
\text { Noventa dias a partir do } \\
\text { surgimento do vício - Art. } \\
\text { 26, II, e art. 26, } \S 3^{\circ} \text {, do } \\
\text { CDC. } \\
\text { Prazo de } 5 \text { anos para ação de } \\
\text { reparação de danos - art. } 27 \\
\text { do CDC. }\end{array}$ & $\begin{array}{c}\text { Para os vícios ocultos } \\
\text { em geral, i.e., } \\
\text { excluídos aqueles que } \\
\text { atinjam a } \\
\text { solidez, segurança e } \\
\text { funcionalidade de } \\
\text { obra, é necessário que } \\
\text { se faça prova de que o } \\
\text { vício era oculto. Na } \\
\text { maioria das vezes é } \\
\text { suficiente provar que } \\
\text { o problema não foi } \\
\text { decorrente de falta de } \\
\text { manutenção ou uso } \\
\text { inadequado da obra. }\end{array}$ \\
\hline
\end{tabular}




\section{RESULTADOS E DISCUSSÕES}

Participaram da primeira etapa de atividade do projeto 113 discentes e um docente do curso de Engenharia Civil do IFTO-Campus Palmas, bem como quatro auditores do TCE-TO. As capacitações dos participantes foram realizadas em maio de 2017 e 2019, conforme figura 1.

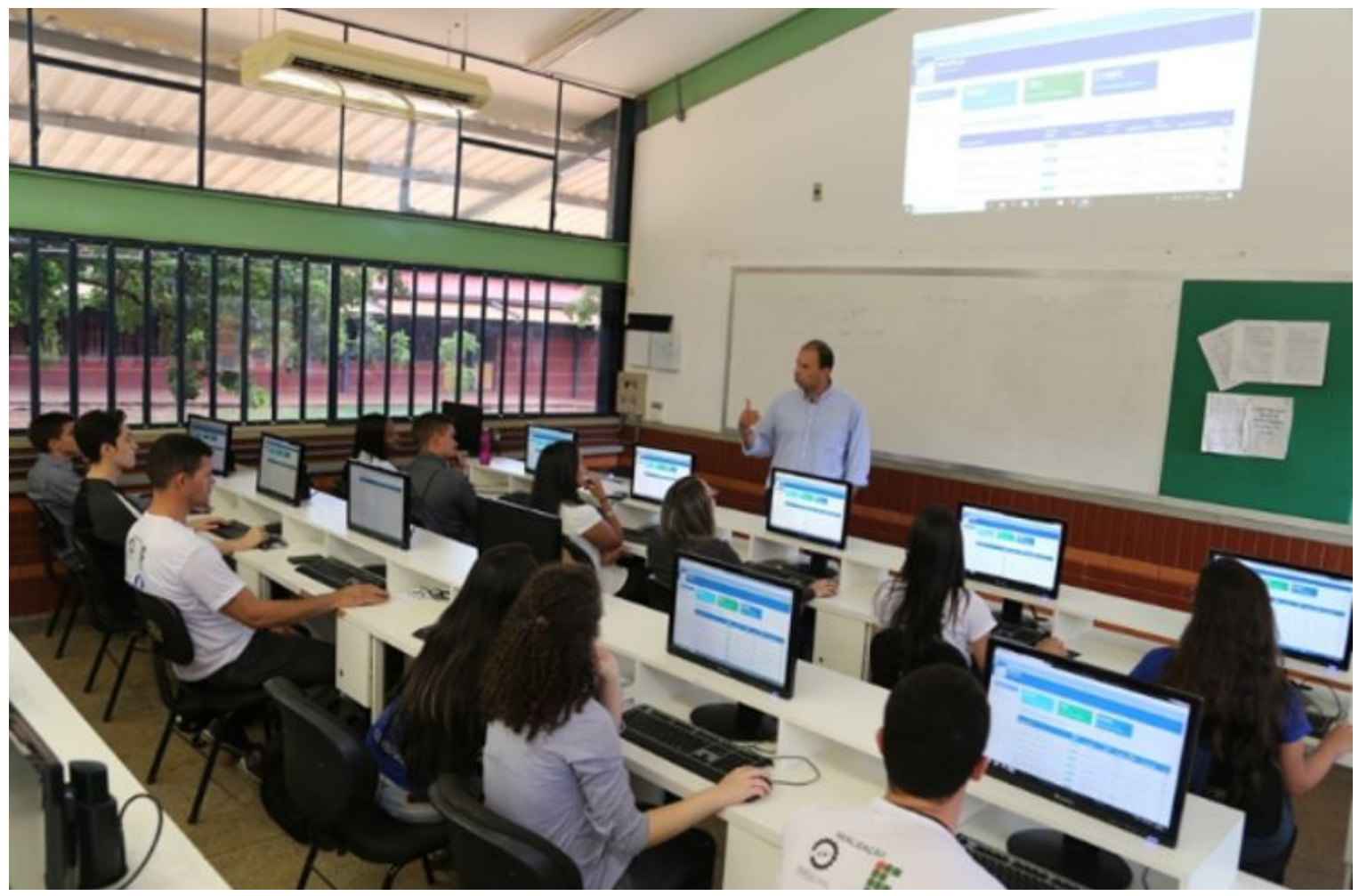

Figura 1 - Registro fotográfico das capacitações dos participantes na primeira e segunda etapa de atividades (2017 e 2019) nos projetos “Fiscalização de obras públicas em parceria com o TCE-TO” e “Auditorias de Qualidade em Obras Públicas”

FONTE: SÊNE (2018), ACADÊMICOS (2019)

As observações realizadas na primeira etapa constituíram base para a execução de 10 manifestações na ouvidoria do TCE-TO, principalmente relacionadas a irregularidades no cadastro de dados do SICAP-LCO. A Tabela 2 apresenta informações sobre as ocorrências disponíveis no portal da ouvidoria do TCE-TO.

Tabela 2 - Manifestações realizadas durante a primeira etapa de atividades, projeto "Fiscalização de obras públicas em parceria com o TCE-TO”

\begin{tabular}{c|c|c|c}
\hline Código da manifestação & \multicolumn{1}{c}{ Objeto do contrato } & Município & Irregularidade \\
\hline $\mathbf{1 7 4 . 1 8 0 . 5 1 1 . 4 9 9}$ & Construção de edificação & Araguaína & Ausência de projeto \\
\hline $\mathbf{1 7 4 . 1 1 0 . 4 1 6 . 0 3 5}$ & Pavimentação e drenagem & Gurupi & Ausência de medições \\
\hline $\mathbf{1 7 8 . 1 3 0 . 0 1 0 . 4 7 9}$ & Construção de edificação & Taguatinga & Ausência de medições \\
\hline $\mathbf{1 7 0 . 1 6 0 . 1 1 2 . 4 5 6}$ & Construção de edificação & Porto Nacional & Ausência de medições \\
\hline $\mathbf{1 7 6 . 1 3 0 . 0 0 0 . 2 9 8}$ & Pavimentação & Itapiratins & Ausência de medições \\
\hline $\mathbf{1 7 2 . 1 5 0 . 8 1 0 . 8 5 1}$ & Pavimentação & Palmas & Problemas de drenagem \\
\hline $\mathbf{1 7 8 . 1 2 0 . 0 1 2 . 8 6 7}$ & $\begin{array}{c}\text { Assistência técnica para } \\
\text { elaboração de projetos }\end{array}$ & Taguatinga & Contrato não registrado \\
\hline $\mathbf{1 7 7 . 1 6 0 . 7 1 1 . 9 1 2}$ & Pavimentação & Paraíso do Tocantins & Ausência de orçamento e projetos \\
\hline $\mathbf{1 7 7 . 1 0 0 . 4 0 9 . 1 4 4}$ & Construção de edificação & Palmas & Irregularidade na modalidade e \\
documentos
\end{tabular}


A seguir a Tabela 3 apresenta os status das manifestações na ouvidoria do TCE-TO, conforme informações disponíveis na Ouvidoria do TCE-TO. Destaca-se que cinco das manifestações foram encerradas, duas aguardam o envio dos documentos e uma encontra-se em análise.

Tabela 3 - Status das manifestações realizadas durante a primeira etapa de atividades, projeto “Fiscalização de obras públicas em parceria com o TCE-TO”

\begin{tabular}{c|c}
\hline Código da manifestação & Status \\
\hline $\mathbf{1 7 4 . 1 8 0 . 5 1 1 . 4 9 9}$ & Arquivos enviados \\
\hline $\mathbf{1 7 4 . 1 1 0 . 4 1 6 . 0 3 5}$ & Irregularidades averiguadas \\
\hline $\mathbf{1 7 8 . 1 3 0 . 0 1 0 . 4 7 9}$ & Arquivos enviados durante execução da obra \\
\hline $\mathbf{1 7 0 . 1 6 0 . 1 1 2 . 4 5 6}$ & Arquivos enviados \\
\hline $\mathbf{1 7 6 . 1 3 0 . 0 0 0 . 2 9 8}$ & Arquivos solicitados, serão analisados pela Corte de Contas \\
\hline $\mathbf{1 7 2 . 1 5 0 . 8 1 0 . 8 5 1}$ & Processo semelhante em tramitação \\
\hline $\mathbf{1 7 8 . 1 2 0 . 0 1 2 . 8 6 7}$ & Aguarda revisão \\
\hline $\mathbf{1 7 7 . 1 6 0 . 7 1 1 . 9 1 2}$ & Arquivos solicitados \\
\hline $\mathbf{1 7 7 . 1 0 0 . 4 0 9 . 1 4 4}$ & Arquivos solicitados, serão analisados pela Corte de Contas \\
\hline $\mathbf{1 7 8 . 1 8 0 . 8 1 3 . 4 4 6}$ & \\
\hline
\end{tabular}

As edificações que constituíram objeto de estudo da segunda etapa de atividades totalizam seis obras, entre edificações de uso de educacional, segurança, prestação de serviços públicos e lazer. A Tabela 4 apresenta a caraterização das edificações visitadas pelos grupos de trabalho durante as atividades de 2018 e 2019 do projeto.

Tabela 4 - Edificações visitadas pelos grupos de trabalho durante segunda etapa de atividades, projeto “Auditorias de Qualidade em Obras Públicas”

\begin{tabular}{|c|c|c|c|c|}
\hline & Serviço & Obra & $\begin{array}{c}\text { Área } \\
\left(\mathrm{m}^{2}\right)\end{array}$ & Município \\
\hline 1 & Construção & Escola de tempo integral Almirante Tamandaré & 9.384 & $\begin{array}{c}\text { Palmas } \\
\text { (TO) }\end{array}$ \\
\hline 2 & Construção & Escola de tempo integral padrão & 10.581 & $\begin{array}{l}\text { Palmas } \\
\text { (TO) }\end{array}$ \\
\hline 3 & Construção & Centro Comunitário com Posto Policial & 270 & $\begin{array}{l}\text { Palmas } \\
\text { (TO) }\end{array}$ \\
\hline 4 & Construção & Centro de Educação Infantil & 707 & $\begin{array}{l}\text { Palmas } \\
\text { (TO) }\end{array}$ \\
\hline 5 & Reforma & Praça da árvore (Parque dos Povos Indígenas) & & $\begin{array}{c}\text { Palmas } \\
\text { (TO) }\end{array}$ \\
\hline 6 & Construção & Fórum de Porto Nacional & 6.746 & Porto Nacional (TO) \\
\hline
\end{tabular}

Essas informações feitas a ouvidoria se converteram em processos autuados no sistema E-contas do TCE-TO, conforme Tabela 5, na qual verifica-se o andamento dos processos. 
Tabela 5 - Situação dos processos no E-contas

\begin{tabular}{cccc}
\hline & Processo no E-contas & Obra & Andamento do processo \\
\hline $\mathbf{1}$ & $9018 / 2018$ & $\begin{array}{c}\text { Escola de tempo integral Almirante } \\
\text { Tamandaré }\end{array}$ & $\begin{array}{c}\text { A empresa informou que irá reparar a } \\
\text { obra }\end{array}$ \\
\hline $\mathbf{2}$ & $9013 / 2018$ & Escola de tempo integral padrão & Empresa notificada \\
\hline $\mathbf{3}$ & $3276 / 2019$ & Centro Comunitário com Posto Policial & Tramitando no TCE \\
\hline $\mathbf{4}$ & $3294 / 2019$ & Centro de Educação Infantil & Tramitando no TCE \\
\hline $\mathbf{5}$ & $3291 / 2019$ & Praça da árvore (Parque dos Povos Indígenas) & Tramitando no TCE \\
\hline $\mathbf{6}$ & $3300 / 2019$ & Fórum de Porto Nacional & Gestor notificado \\
\hline
\end{tabular}

Os processos 9013/2018 e 9018/2018 foram analisados pelo Auditor de Controle Externo Robson Peixoto de Oliveira; os processos 3276/2019 e 3291/2019 pelo Auditor de Controle Externo Eduardo Pereira Valim; e os processos 3294/2019 e 3300/2019 pelo Auditor de Controle Externo Joselito Alves de Macedo.

\section{CONCLUSÕES}

A participação social nas políticas públicas, através do controle social, corresponde a "uma moderna compreensão de relação Estado-sociedade, onde a esta cabe estabelecer práticas de vigilância e controle sobre aquele” (CARVALHO, 1995, p. 8). Ações realizadas com intuito de fortalecer a relação entre cidadãos e órgãos de controle repercutem de forma significativa no estímulo ao exercício da cidadania e instrumentalização desses atores.

Do mesmo modo, o conjunto das atividades realizadas no âmbito dos projetos "Fiscalização de obras públicas em parceria com o TCE-TO” e “Auditorias de Qualidade em Obras Públicas” pelo IFTO-Campus evidenciam resultados parciais positivos, representados pela adesão das instituições de ensino superior ao projeto, e pela participação dos docentes e discentes capacitados a utilizar as ferramentas, disponibilizadas pelo próprio órgão fiscalizador no exercício do seu papel cidadão.

Devido aos resultados positivos do Projeto “Auditorias de Qualidade em Obras Públicas” desenvolvido pelo IFTOCampus Palmas, esse Projeto foi assinado entre o TCE-TO e o IFTO-Campus Palmas, para ser desenvolvido no âmbito das obras públicas do Estado do Tocantins.

\section{REFERÊNCIAS}

ACADÊMICOS participam de capacitação para a fiscalização de obras públicas. Tribunal de Contas do Estado do Tocantins. Palmas, 18 de maio de 2019. Disponível em: <https://www.tce.to.gov.br/sitetce/sala-deimprensa/noticias/item/2591-acad\%C3\%AAmicos-participam-de-capacita\%C3\%A7\%C3\%A3o-para-afiscaliza\%C3\%A7\%C3\%A3o-de-obras-p\%C3\%BAblicas>. Acesso em: 21 abr. 2019.

BRASIL. Constituição. Constituição da República Federativa do Brasil. Brasília, DF: Senado Federal, 1988.

Lei $n^{\circ}$ 8.666, de 21 de junho de 1993. Regulamenta o art. 37, inciso XXI, da Constituição Federal, institui normas para licitações e contratos da Administração Pública e dá outras providências. Diário Oficial da União, Brasília, DF, 06 de julho de 1993.

. Lei $\mathrm{n}^{\circ}$ 12.527, de 18 de novembro de 2011. Regula o acesso a informações previsto no inciso XXXIII do art. 5o, no inciso II do § 3o do art. 37 e no $\S 2$ o do art. 216 da Constituição Federal; altera a Lei no 8.112, de 11 de dezembro de 1990; revoga a Lei no 11.111, de 5 de maio de 2005, e dispositivos da Lei no 8.159, de 8 de janeiro de 1991; e dá outras providências. Diário Oficial da União, Brasília, DF, 18 de novembro de 2011.

Controladoria-Geral da União. Controle Social Orientações aos cidadãos para participação na gestão pública e exercício do controle social. $3^{\circ}$ ed. Disponível em: <https://www.cgu.gov.br/Publicacoes/controlesocial/arquivos/controlesocial2012.pdf>. Acesso em: 22 abr. 2019.

PASCOAL, V. F.; FARIAS, W. B. O papel dos tribunais de contas no fortalecimento do controle social: o Programa TCEndo Cidadania do TCE-PE. Revista do Tribunal de Contas do Estado de Minas Gerais, v. XXX, p. 154-157, 2012. Disponível em: <http://revista1.tce.mg.gov.br/Content/Upload/Materia/1685.pdf>. Acesso em: 22 abr. 2019. 
RICCI, R. Controle social: um conceito e muitas confusões. In: Revista espaço acadêmico, n. 98, jul. 2009. Disponível em: <http://eduem.uem.br/ojs/index.php/EspacoAcademico/article/viewFile/7590/4362>. Acesso em: 21 abr. 2019.

SÊNE, A. Fiscais dos gastos públicos. Jornal do Tocantins, Palmas, 09 de dezembro de 2017. Disponível em: <https://www.jornaldotocantins.com.br/editorias/politica/fiscais-dos-gastos-p\%C3\%BAblicos-1.1413478>. Acesso em: 21 abr. 2019.

SILVA, G. A. Fiscalização participativa: a capacitação do cidadão para o controle social. 2007. Dissertação (Mestrado Profissional em Gestão e Pública para o Desenvolvimento do Nordeste) - Universidade Federal de Pernambuco, Recife, 2007.

TOCANTINS. Tribunal de Contas do Estado. Instrução Normativa TCE/TO No 10 de 11 de dezembro de 2008. Institui e regulamenta o SICAP-LCO, Sistema Integrado de Controle e Auditoria Pública - Licitações e Obras, no âmbito do Tribunal de Contas do Estado do Tocantins e dispõe sobre a remessa de dados de Procedimento Licitatórios e informações sobre as obras e serviços de engenharia por meio eletrônico com a assinatura digital, pelos órgãos da administração direta e indireta do Estado e Municípios. Boletim Oficial do TCE/TO, v. 1, n. 13, 19 de dezembro de 2008.

NOGUEIRA, Carnot Leal. Auditoria de qualidade de obras públicas. 1. ed. São Paulo: Pini, 2008. 192p. 